\title{
Kinetics of direct and substrate-mediated electron transfer of versatile peroxidase-modified graphite electrodes
}

\author{
Florentina-Daniela Munteanu ${ }^{a}$, Francisco J. Ruiz-Dueñas ${ }^{b}$, \\ Angel T. Martínez ${ }^{\mathrm{b}}$, Artur Cavaco-Paulo ${ }^{\mathrm{a}, *}$ \\ ${ }^{a}$ Department of Textile Engineering, University of Minho, Campus de Azurem, 4800-058 Guimarães, Portugal \\ ${ }^{\mathrm{b}}$ Centro de Investigaciones Biológicas, CSIC, Ramiro de Maeztu 9, E-28040 Madrid, Spain
}

Received 3 December 2004; received in revised form 22 February 2005; accepted 28 February 2005

Available online 8 April 2005

\begin{abstract}
Electron transfer (ET) of versatile peroxidase (VP) was studied in the bioelectrocatalytic reduction reaction of $\mathrm{H}_{2} \mathrm{O}_{2}$ at peroxidase-modified graphite electrodes to obtain additional information on the kinetic characteristics of this novel ligninolytic peroxidase. Rotating disk electrodes (RDE) experiments were performed at $0 \mathrm{~V}$ (vs. SCE) in two different buffers (tartrate buffer, pH 5.0; and citrate buffer, $\mathrm{pH}$ 3.0). From measurements of the mediated and mediatorless currents of $\mathrm{H}_{2} \mathrm{O}_{2}$ reduction at the RDE, the percentage of VP molecules involved in direct ET $(\approx 55 \%)$ was calculated. The peroxidase-modified electrodes were used for determination of the donor substrates in RDE mode, and the results were interpreted in terms of catalytic efficiencies.

(c) 2005 Elsevier B.V. All rights reserved.
\end{abstract}

Keywords: Bioelectrocatalysis; Versatile peroxidase; Heterogeneous electron transfer; Graphite electrode

\section{Introduction}

Versatile peroxidase (VP) is a novel heme peroxidase type described in fungi from the genera Pleurotus and Bjerkandera, whose biochemical, molecular and structural aspects are being thoroughly investigated [1-5]. The most intriguing characteristics of this new enzyme is its ability to use a variety of electron donor substrates that were previously considered as characteristic of other peroxidase types, such as manganese peroxidase $(\mathrm{MnP})$ lignin peroxidase (LiP) and horseradish peroxidase (HRP) $[6,7]$.

A common feature of all heme peroxidases is that their active sites contain similar prosthetic groups that, for a majority of known plant and microbial peroxidases, is a heme $\mathrm{b}$ or ferriprotoporphyrin IX [8].

\footnotetext{
${ }^{*}$ Corresponding author. Fax: +351 253510271.

E-mail address: artur@det.uminho.pt (A. Cavaco-Paulo).
}

Peroxidases catalyze the oxidation of various electron donor substrates (e.g., phenols and aromatic amines) by $\mathrm{H}_{2} \mathrm{O}_{2}$ [8]. In the catalytic cycle, the ferric resting peroxidase experiments a two-electron oxidation by peroxide to yield compound I (with a reaction constant $k_{1}$ ), which is reduced back in two one electron reactions by two molecules of substrate $\left(\mathrm{AH}_{2}\right)$ that are oxidized to the corresponding radical $\left(\mathrm{AH}^{\cdot}\right)$ (with reaction constants $k_{2}$ and $k_{3}$ ). If peroxidase is immobilized on a graphite electrode, the electrode can substitute the electron donor substrates in the common peroxidase cycle. This process is usually referred to as direct electron transfer (ET) $[9,10]$. Peroxidase is oxidized by $\mathrm{H}_{2} \mathrm{O}_{2}$, and then subsequently reduced by electrons provided by the electrode as shown in the following reaction:

$\mathrm{Cpd} \mathrm{I}+2 \mathrm{e}^{-}+2 \mathrm{H}^{+} \stackrel{k_{\mathrm{s}}}{\rightarrow} \mathrm{POD}+\mathrm{H}_{2} \mathrm{O}$

When both $\mathrm{H}_{2} \mathrm{O}_{2}$ and an aromatic electron donor $\mathrm{AH}_{2}$, e.g., $p$-cresol, hydroquinone or catechol, are present at a 
peroxidase electrode, direct ET coexists with the common enzymatic reaction. The enzymatically formed oxidized donors $\left(\mathrm{AH}^{-}\right)$are rapidly electrochemically reduced at the electrode at an appropriate applied potential according to the following reaction:

$\mathrm{AH}^{\cdot}+\mathrm{e}^{-}+\mathrm{H}^{+} \stackrel{k_{\mathrm{s}, \mathrm{m}}}{\rightarrow} \mathrm{AH}_{2}$

This case is known as mediated ET, which is usually more efficient compared with direct ET [11,12]. The mediated ET can also be used analytically to determine the concentration of the mediators (e.g., phenols and aromatic amines) when using a constant $\mathrm{H}_{2} \mathrm{O}_{2}$ concentration [1214]. The search for new peroxidases with higher catalytic activity and/or broad or narrow selectivity toward various aromatic compounds also serves the purpose of improving peroxidase-based analytical systems. Although mediated and direct ET occur simultaneously at the peroxidase electrode, the individual peroxidase molecules are not equally involved in the two processes. A kinetic model has earlier been developed to determine the fraction of adsorbed peroxidase molecules that is able to communicate with the electrode via direct ET [10-12]. The developed model also allows calculations of the rate constants $\left(k_{\mathrm{s}}, k_{1}\right.$ and $\left.k_{3}\right)$ corresponding to the bioelectrocatalytic reaction of the immobilized peroxidases.

The peroxidase used in the present study is a recombinant VP expressed in Escherichia coli and activated in vitro, which shows the same catalytic properties of the wild enzyme from Pleurotus eryngii [15]. The aim of the study was to investigate the catalytic properties of VP immobilized onto graphite electrodes using different electron donor substrates and to find the electron transfer characteristics of this new peroxidase.

\section{Experimental}

\subsection{Chemicals}

Recombinant VP was obtained by expressing the cDNA of the allelic variant VPL2 of $P$. eryngii in $E$. coli followed by protein refolding in the presence of heme, as previously reported [15].

Citrate buffer salts were of analytical grade and obtained from Merck, Darmstadt, Germany. Tartrate buffer salts, and the enzyme substrates veratryl $(3,4-$ dimethoxybenzyl) alcohol, methoxy-p-hydroquinone, 2,6-dimethoxyphenol and Orange IV (C.I. 13080; Acid Orange 5) (an azo dye) were purchased from Sigma, St. Louis, MO, USA (see Fig. 1). All aqueous solutions were prepared using distilled water.

\subsection{Electrode preparation}

The VP electrodes were prepared using rods of solid spectroscopic graphite (SGL Carbon, Werke Ringsdorff, (a)<smiles>COc1ccc(C=O)cc1OC</smiles>

(b)<smiles>COc1cc(O)ccc1O</smiles>

(c)<smiles>COc1cccc(OC)c1O</smiles>

(d)

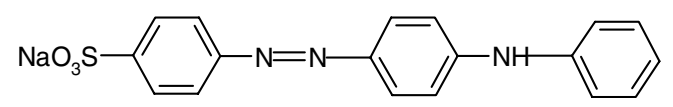

Fig. 1. Chemical structures of the veratryl alcohol (a), methoxy-phydroquinone (b), 2,6-dimethoxyphenol (c), and Orange IV (d).

Bonn, Germany, type RW001, $3.05 \mathrm{~mm}$ diameter). The graphite rods were first polished on wet fine-structured emery paper (grit size: P1200) and then additionally polished on paper to obtain a mirror-like surface. The electrode rods were carefully rinsed with deionized water and allowed to dry at room temperature. A $5 \mu \mathrm{l}$ aliquot of the VP solution $(3.7 \mathrm{mg} / \mathrm{ml}$ protein in $10 \mathrm{mM}$ tartrate buffer, $\mathrm{pH}$ 5.0) was added to each of the polished ends of the graphite rods and the adsorption was allowed to proceed for $1 \mathrm{~h}$ at $4{ }^{\circ} \mathrm{C}$. The enzyme electrodes were then thoroughly rinsed with $10 \mathrm{mM}$ tartrate buffer, $\mathrm{pH}$ 5.0, and if not immediately used, they were stored in the same buffer at $4{ }^{\circ} \mathrm{C}$. Weakly adsorbed peroxidase was desorbed before measurements, by rotating the electrode in buffer for at least $30 \mathrm{~min}$.

\subsection{Amperometric measurements}

The enzyme electrode was fitted into a rotating disk electrode holder (RDE; Radiometer Analytical, Villeurbanne, France, model EDI101), which was placed in a three-electrode cell with an $\mathrm{Ag} \mid \mathrm{AgCl}(3 \mathrm{M} \mathrm{NaCl})$ reference electrode (BAS, Bioanalytical Systems, West Lafayette, IN, USA) and a platinum wire auxiliary electrode. The electrodes were connected to a Voltalab 30 Potentiostat (Radiometer Analytical) controlled by the Voltamaster 4 (version 5.6) electrochemical software. All measurements were performed at an applied potential of $-50 \mathrm{mV}$ vs. $\mathrm{Ag} \mid \mathrm{AgCl}[11,12]$ with an electrolyte of $10 \mathrm{mM}$ tartrate buffer, $\mathrm{pH} 5.0$ (or $0.1 \mathrm{M}$ citrate buffer $\mathrm{pH} 3.0$, in specified cases). The current was registered using various rotation speeds $(200-1000 \mathrm{rpm})$ and $\mathrm{H}_{2} \mathrm{O}_{2}$ :substrate concentrations. Prior to experiments, the solution was bubbled with nitrogen for $15 \mathrm{~min}$. Nitrogen was passed over the solution during the experiments. 


\section{Results and discussion}

To compare the bioelectrochemical properties of VP with other studied peroxidases [10-12,16-20], the kinetic constants for direct and mediated ET were estimated from the RDE experiments using the Koutecky-Levich approach and methodology described previously $[11,12]$. The measured current, $I$, is a combination of both the mass-transfer limited current, $I_{\text {lim }}$, and the kinetically limited current, $I_{\text {kin }}$, according to the following equation:

$1 / I=1 / I_{\lim }+1 / I_{\text {kin }}$.

The mass-transfer can be changed by (i) varying the rotation speed using RDE or (ii) varying the concentration of the substrate in the solution. $I_{\text {kin }}$ can be calculated by extrapolating the dependence of the registered current $(I)$ on the rotation speed in Koutecky-Levich plots, i.e., the intercept of the Koutecky-Levich plot is equal to the inverse of $I_{\text {kin. }} I_{\text {kin }}$ depends on the $\mathrm{H}_{2} \mathrm{O}_{2}$ concentration. In the case of direct ET, this dependence can be expressed as follows [10-12]:

$1 / I_{\text {kin }}=1 / n F E_{\text {DET }}\left(1 / k_{1} c^{*}+1 / k_{\mathrm{s}}\right)$,

where $n$ is the number of electrons transferred per $\mathrm{H}_{2} \mathrm{O}_{2}$ molecule $(n=2), c^{*}$ is the bulk concentration of $\mathrm{H}_{2} \mathrm{O}_{2}$, $E_{\mathrm{DET}}$ is the amount of adsorbed enzyme active in direct ET and $F$ is the Faraday constant $\left(96484 \mathrm{C} \mathrm{mol}^{-1}\right)$. By fitting the dependence of $I_{\text {kin }}$ against the $\mathrm{H}_{2} \mathrm{O}_{2}$ concentration according to Eq. (4), the kinetic constants $k_{1}$ and $k_{\mathrm{s}}$ can be evaluated. In the case of mediated ET at a saturating concentration (a concentration sufficiently high so that all peroxidase molecules work in mediated ET) of a one-electron donor $\left(\mathrm{AH}_{2}\right), I_{\text {kin }}$ can be expressed as follows:

$1 / I_{\text {kin }}=1 / 2 n_{1} F E\left(1 / k_{1} c^{*}+1 / k_{3}\left[\mathrm{AH}_{2}\right]\right)$,

where $n_{1}$ is the number of electrons transferred per donor molecule $\left(n_{1}=1\right), E$ is the total amount of active enzyme on the electrode surface, $k_{3}$ is the rate-limiting constant for the enzyme reduction by $\mathrm{AH}_{2}\left(k_{2} \gg k_{3}\right)$
$[10,12]$. By fitting the dependence of $I_{\text {kin }}$ against the $\mathrm{H}_{2} \mathrm{O}_{2}$ concentration according to Eq. (5), the kinetic constants $k_{1}$ and $k_{3}$ can be evaluated. The basic assumption is that in the presence of saturating concentrations of a soluble electron donor, acting as an ET mediator, all peroxidase molecules work in mediated ET whereas in its absence only some portion of the molecules is active in direct ET.

From the slopes of the Koutecky-Levich plots the number of electrons $(n)$ was calculated and was found being close to the theoretical value of 2 . The mean value of $n$ from measurements with five electrodes is presented in Table 1. The intercepts of the KouteckyLevich plots corresponded to the reciprocal of the kinetically limited currents, $I_{\text {kin. }}$. The values of $I_{\text {kin }}^{-1}$ plotted vs. $\left[\mathrm{H}_{2} \mathrm{O}_{2}\right]^{-1}$ (Fig. 2) allow us to calculate the rate constants $k_{\mathrm{s}}, k_{1}$ and $k_{3}$, which characterize the overall process of the bioelectroreduction of $\mathrm{H}_{2} \mathrm{O}_{2}$ catalyzed

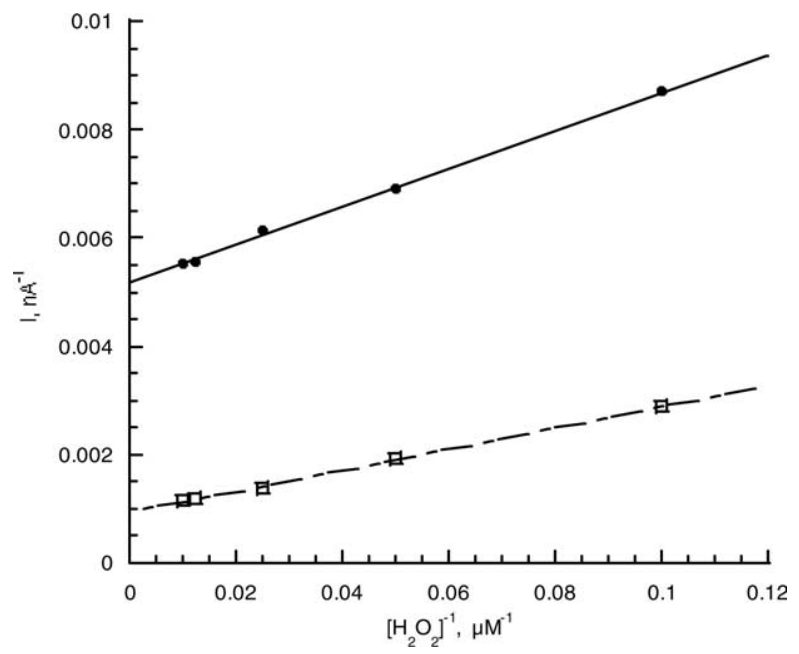

Fig. 2. $I_{\text {kin }}$ (obtained as intercepts in Koutecky-Levich plots) as a function of the $\mathrm{H}_{2} \mathrm{O}_{2}$ concentration for graphite electrodes modified with VP in absence (-) and ( $\square$ ) in presence of $100 \mu \mathrm{M} \mathrm{2,6-}$ dimethoxyphenol (saturating concentration). $0.1 \mathrm{M}$ tartrate buffer, $\mathrm{pH}$ 5.0, used as electrolyte.

Table 1

Percentage of active peroxidase molecules in direct ET, and electrochemically determined rate constants for VP adsorbed on graphite electrodes

\begin{tabular}{|c|c|c|c|c|c|}
\hline & Direct ET (\%) & $k_{1}\left(10^{-5} \mathrm{~s}^{-1} \mathrm{M}^{-1}\right)$ & $k_{\mathrm{s}}\left(\mathrm{s}^{-1}\right)$ & $k_{3}\left(10^{-4} \mathrm{~s}^{-1} \mathrm{M}^{-1}\right)$ & $n$ \\
\hline \multicolumn{6}{|l|}{ Tartrate buffer ( $p H$ 5.0) } \\
\hline Veratryl alcohol & $55.0 \pm 3.1$ & $1.4 \pm 0.8$ & $1.7 \pm 0.7$ & $1.4 \pm 0.7$ & $1.7 \pm 0.4$ \\
\hline Dimethoxyphenol & $54.7 \pm 4.5$ & $2.5 \pm 0.7$ & $1.8 \pm 0.2$ & $5.3 \pm 2.4$ & $1.5 \pm 0.1$ \\
\hline Methoxyhydroquionone & $55.2 \pm 4.1$ & $1.1 \pm 0.7$ & $1.6 \pm 0.3$ & $5.6 \pm 1.8$ & $1.5 \pm 0.1$ \\
\hline Orange IV & $58.9 \pm 5.3$ & $1.4 \pm 0.3$ & $5.5 \pm 0.8$ & $2.3 \pm 0.9$ & $2.1 \pm 0.2$ \\
\hline \multicolumn{6}{|l|}{ Citrate buffer ( $p H$ 3.0) } \\
\hline Veratryl alcohol & $53.7 \pm 3.2$ & $1.2 \pm 0.8$ & $7.3 \pm 0.5$ & $2.5 \pm 0.2$ & $2.0 \pm 0.2$ \\
\hline Dimethoxyphenol & $54.0 \pm 4.2$ & $1.0 \pm 0.3$ & $3.1 \pm 0.4$ & $1.2 \pm 0.2$ & $1.8 \pm 0.3$ \\
\hline Methoxyhydroquionone & $56.1 \pm 2.8$ & $0.9 \pm 0.4$ & $4.5 \pm 0.5$ & $4.9 \pm 0.4$ & $1.8 \pm 0.2$ \\
\hline Orange IV & $54.9 \pm 1.6$ & $1.5 \pm 0.5$ & $2.5 \pm 0.3$ & $6.5 \pm 1.0$ & $2.0 \pm 0.3$ \\
\hline
\end{tabular}

Results obtained using $\mathrm{pH} 5$ or $\mathrm{pH} 3$ buffers as electrolyte solution. 
by the adsorbed peroxidase. The ratio of the slopes obtained in the presence and in the absence of a saturating concentration of the electron donor gives the ratio between the amount of the adsorbed enzyme active in direct ET, $E_{\mathrm{DET}}$, and the total amount of the active enzyme adsorbed at the electrode surface [11], in accordance with Eqs. (4) and (5). It should be mentioned that for the calculation of the kinetic constants the surface concentration of active peroxidase should be known. As a first approximation, 40 pmol of peroxidase per $\mathrm{cm}^{2}$ of the geometric electrode surface area was used, as discussed below [10-12,18,21,22]. It should be emphasized that the ratio between the enzyme active in direct ET and the total enzyme is not dependent upon the amount of enzyme on the electrode surface and thus, various peroxidases can easily be compared on this basis.

\subsection{Kinetic constants}

The kinetic results obtained from processing the amperometric data are shown in Table 1. It can be seen that VP shows a higher percentage of molecules in direct ET than it was found for native HRP $(45 \%)$, native LiP $(9.4 \%)$ or for native $\mathrm{MnP}(27 \%)$ but the value is similar to what it was found for a mutant of MnP (S168W) [17]. These differences are probably related to protein glycosylation degrees as discussed below.

As described above, the rate constants $\left(k_{\mathrm{s}}, k_{1}\right.$ and $\left.k_{3}\right)$ can be calculated by fitting the data to Eqs. (4) and (5), if the enzyme concentration on the electrode is known. The calculation of the rate constants suffers from that the number of adsorbed and active enzyme molecules remains unknown and that it is a serious and still unresolved problem for peroxidase adsorbed on graphite surfaces since there is no irreversible peroxidase inhibitor that allows the titration of the enzyme active centers to be performed neither in solution nor on the electrode surface [12]. However, peroxidases are not expected to adsorb on solids with higher coverage than a monolayer [23]. In our calculations, we therefore assume for monolayer coverage of adsorbed peroxidase on the electrode surface of $40 \mathrm{pmol} \mathrm{cm}^{-2}[10-12,18,21,22]$. Although the absolute values of the rate constants obtained from electrochemical kinetics (Table 1) are not very precise (since the true surface concentration of peroxidase remains unknown) this method can be used to compare various plant and microbial peroxidases as a first approach, assuming their equal concentration on the electrode surface.

The degree of direct electron transfer may also depend upon the degree of glycosylation of the peroxidase. The electrodes modified with recombinant VP show higher percentages of properly oriented molecules than in the case of electrodes modified with wild (non-recombinant) HRP ( $21 \%$ glycosylation), with MnP (17\% gly- cosylation), while for LiP varies between $6 \%$ and $13 \%$. We ascribed this difference to the absence of oligosaccharide chains in the recombinant VP obtained from E. coli. It can be concluded, based on the electrochemistry of this enzyme, that glycosylation hinders direct electron transfer either because of the insulating effect of the sugar moieties or because of the increased distance between the electrode and the heme.

The obtained rate constants of the reaction between the peroxidase and $\mathrm{H}_{2} \mathrm{O}_{2}\left(k_{1}\right)$ vary with some extent but this small variation can be attributed to the amount of enzyme adsorbed onto the electrode surface. Comparing the data shown in Table 1 with the previous published results [15] we can conclude that $k_{1}$ for this peroxidase decreases more than 10 times when changing from catalysis in solution to catalysis by peroxidase immobilized at the electrode surface.

It is interesting to note that the rate constants of the heterogeneous ET, $k_{\mathrm{s}}$, between the VP and graphite are of the same order of magnitude as for other known peroxidases $\left(2.3 \mathrm{~s}^{-1}\right.$ for HRP, $1.67 \mathrm{~s}^{-1}$ for native $\mathrm{MnP}$, and $1.6 \mathrm{~s}^{-1}$ for LiP) [17].

Beside this, it was observed that the buffer $\mathrm{pH}$ does affect the efficiency of direct ET between graphite and VP: the value of $k_{\mathrm{s}}$ is increasing about 2 times when going from $\mathrm{pH} 5.0$ to $\mathrm{pH}$ 3.0. Exception makes Orange $\mathrm{IV}$, for which $k_{\mathrm{s}}$ is decreasing when the solution $\mathrm{pH}$ is changed to $\mathrm{pH} 3.0$, results that at the moment are not fully understood and further experiments are necessary to understand this behavior.

The effect of $\mathrm{pH}$ on the kinetics of the direct ET between gold electrodes and adsorbed HRP was earlier studied and it was found that a decrease in $\mathrm{pH}$ from 8.0 to 6.0 does not affect the rate of the bioelectrocatalytic reduction of $\mathrm{H}_{2} \mathrm{O}_{2}\left(k_{1}\right)$, but increases the rate of the direct ET. In the case of the $\mathrm{C}$-terminus histidine mutant the heterogeneous ET constants increased 40 times, from $12 \mathrm{~s}^{-1}$ at $\mathrm{pH} 8.0$ to $\sim 500 \mathrm{~s}^{-1}$ at $\mathrm{pH} 6.0$ [24].

\subsection{Determination of the catalytic efficiencies for the electron donor oxidation}

The peroxidase electrodes were used to determine the mediators in the RDE mode. Each experiment started having just the buffer in the system. When a stable baseline was achieved, the enzyme substrate, $\mathrm{H}_{2} \mathrm{O}_{2}(100 \mu \mathrm{M}$ final concentration), was added to the system and a steady-state current due to the direct ET was registered. If the sample containing a donor substrate is added in the peroxidase system, enzymatic oxidation of the mediators results in radicals that can be electrochemically rereduced at the electrode $(-50 \mathrm{mV}$ vs. $\mathrm{Ag} \mid \mathrm{AgCl})$, resulting in a reduction current proportional to the substrate concentration. Representative calibration curves are presented in Fig. 3. In all cases the VP-electrodes displayed Michaelis-Menten like kinetics. The kinetics of 


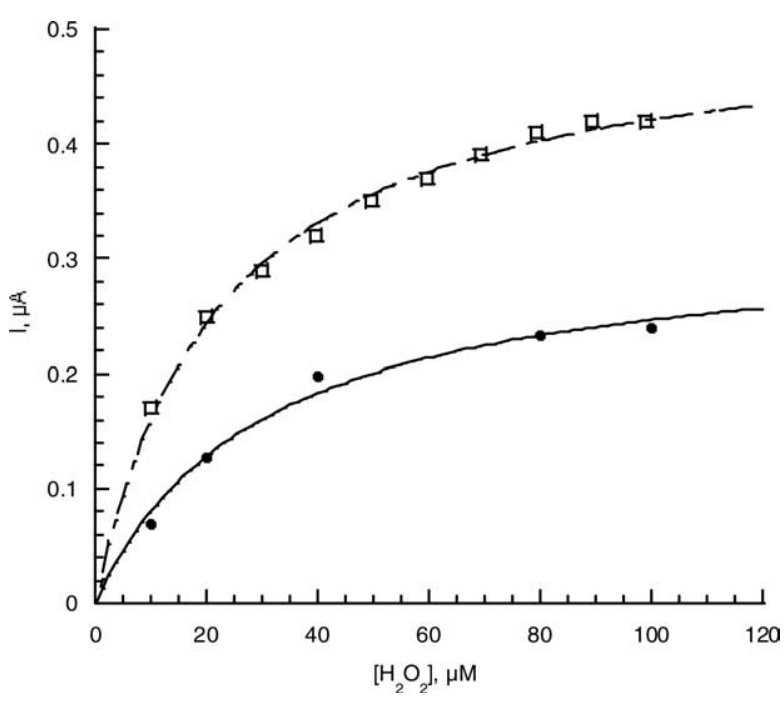

Fig. 3. Calibration curves for the determination of veratryl alcohol using as electrolyte $(\bullet) 0.1 \mathrm{M}$ tartrate buffer, $\mathrm{pH} 5.0$, and $(\square) 0.1 \mathrm{M}$ citrate buffer, $\mathrm{pH}$ 3.0.

mediated peroxidase catalyzed reactions are firstly affected by the affinity between enzyme and the mediator. An estimation of this influence can be done by amperometric measurements in terms of $I_{\max } / K_{\mathrm{m}}^{\mathrm{app}}$ ratio. These parameters are often calculated in the design of enzymatic sensors to evaluate the sensitivity of the system proposed, which is related to the low or high affinity of the enzyme towards a specific substrate. Lower $K_{\mathrm{m}}^{\mathrm{app}}$ values at similar catalytic currents involved higher effectiveness of the enzyme at lower mediator concentrations.

As can be seen from Table 2 it seems that for all the tested substrates there is an improvement in the catalytic efficiency when the electrolyte is changed to $0.1 \mathrm{M}$ citrate buffer, $\mathrm{pH}$ 3.0. Thus the $K_{\mathrm{m}}^{\mathrm{app}}$ values obtained for the experiments performed in citrate buffer, $\mathrm{pH} 3.0$, are lower showing that the enzyme has a higher affinity for the substrates at low $\mathrm{pH}$.

Table 2

Michaelis-Menten constants

\begin{tabular}{llrl}
\hline & $I_{\max }(\mu \mathrm{A})$ & $K_{\mathrm{m}}^{\mathrm{app}}(\mu \mathrm{M})$ & $\begin{array}{l}I_{\max } / K_{\mathrm{m}}^{\mathrm{app}} \\
\left(\mathrm{A} / \mathrm{M}^{-1} \mathrm{~cm}^{-2}\right)\end{array}$ \\
\hline Tartrate buffer $(p H$ 5.0) & & & \\
Veratryl alcohol & 0.32 & 30.0 & 0.15 \\
Dimethoxyphenol & 0.62 & 108.2 & 0.08 \\
Methoxyhydroquinone & 1.12 & 91.1 & 0.16 \\
Orange IV & 0.17 & 44.8 & 0.06 \\
Citrate buffer ( $p$ H 3.0) & & & \\
Veratryl alcohol & 0.51 & 22.1 & 0.32 \\
Dimethoxyphenol & 0.29 & 48.3 & 0.08 \\
Methoxyhydroquinone & 0.26 & 13.8 & 0.26 \\
Orange IV & 0.25 & 24.6 & 0.14 \\
\hline
\end{tabular}

\section{Conclusions}

VP was shown to display significant bioelectrocatalytical activity for the reduction of $\mathrm{H}_{2} \mathrm{O}_{2}$. The rate constants of the heterogeneous ET, $k_{\mathrm{s}}$, between graphite and VP were close to the values that are known for the native HRP $\left(2.3 \mathrm{~s}^{-1}\right)$ [17]. This implies that for this new enzyme (VP) the ET pathways do not principally differ from other peroxidases. The present study also reveals that VP has the potential for analytical applications. This peroxidase was shown to possess optimal bioelectrocatalytical properties for a possible further development of peroxidase-modified biosensors for azo dyes detection/degradation.

\section{Acknowledgments}

The work was financially supported by the Portuguese Foundation of Science and Technology (FCT) providing a grant to Florentina-Daniela Munteanu (SFRH/BPD/16674/2004), and the Biotechnology Programme of the Spanish MEC (BIO2002-01166). Francisco J. Ruiz-Dueñas thanks an I3P contract from the Spanish CSIC.

\section{References}

[1] M.J. Martínez, A.T. Martínez, in: K.M.a.E. Srebotnik (Ed.), Biotechnology in the Pulp and Paper Industry: Recent Advances in Applied and Fundamental Research, Facultas-Universitätsverlag, Vienna, 1996, pp. 417-420.

[2] F.J. Ruiz-Dueñas, M.J. Martínez, A.T. Martínez, Mol. Microbiol. 31 (1999) 223-236.

[3] S. Camarero, S. Sarkar, F.J. Ruiz-Dueñas, M.J. Martínez, A.T. Martínez, J. Biol. Chem. 274 (1999) 10324-10330.

[4] T. Mester, J.A. Field, J. Biol. Chem. 273 (1998) 15412-15417.

[5] L. Banci, S. Camarero, A.T. Martínez, M.J. Martínez, M. PérezBoada, R. Pierattelli, F.J. Ruiz-Dueñas, J. Biol. Inorg. Chem. 8 (2003) 751-760.

[6] A.T. Martinez, Enzyme Microb. Technol. 30 (2002) 425-444.

[7] A. Heinfling, F.J. Ruiz-Dueñas, M.J. Martínez, M. Bergbauer, U. Szewzyk, A.T. Martínez, FEBS Lett. 428 (1998) 141-146.

[8] H.B. Dunford, Heme Peroxidase Nomenclature (1999) 65-71.

[9] A.L. Ghindilis, P. Atanasov, E. Wilkins, Electroanalysis 9 (1997) 661-674.

[10] L. Gorton, A. Lindgren, T. Larsson, F.D. Munteanu, T. Ruzgas, I. Gazaryan, Anal. Chim. Acta 400 (1999) 91-108.

[11] T. Ruzgas, L. Gorton, J. Emnéus, G. Marko-Varga, J. Electroanal. Chem. 391 (1995) 41-49.

[12] A. Lindgren, F.-D. Munteanu, I.G. Gazaryan, T. Ruzgas, L. Gorton, J. Electroanal. Chem. 458 (1998) 113-120.

[13] T. Ruzgas, J. Emnéus, L. Gorton, G. Marko-Varga, Anal. Chim. Acta 311 (1995) 245-253.

[14] F.-D. Munteanu, A. Lindgren, J. Emnéus, L. Gorton, T. Ruzgas, E. Csöregi, A. Ciucu, R.B. van Huystee, I.G. Gazaryan, L.M. Lagrimini, Anal. Chem. 70 (1998) 2596-2600.

[15] M. Perez-Boada, W.A. Doyle, F.J. Ruiz-Duenas, M.J. Martinez, A.T. Martinez, A.T. Smith, Enzyme Microb. Technol. 30 (2002) $518-524$. 
[16] M.J. Martinez, F.J. Ruiz-Duenas, F. Guillen, A.T. Martinez, Eur. J. Biochem. 237 (1996) 424-432.

[17] E.E. Ferapontova, N.S. Reading, S.D. Aust, T. Ruzgas, L. Gorton, Electroanalysis 14 (2002) 1411-1418.

[18] A. Lindgren, M. Tanaka, T. Ruzgas, L. Gorton, I. Gazaryan, K. Ishimori, I. Morishima, Electrochem. Commun. 1 (1999) 171-175.

[19] A. Lindgren, T. Ruzgas, L. Gorton, G.B. Ardila, I.Y. Sakharov, I.G. Gazaryan, Biosens. Bioelectron. 15 (2000) 491-497.
[20] A. Lindgren, T. Ruzgas, L. Gorton, Curr. Top. Anal. Chem. 2 (2001) 71-94.

[21] T. Tatsuma, Y. Okawa, T. Watanabe, Anal. Chem. 61 (1989) 2352-2355.

[22] R.M. Paddock, E.F. Bowden, J. Electroanal. Chem. 260 (1989) 487-494.

[23] J.D. Andrade, V. Hlady, Adv. Polym. Sci. 79 (1986) 1-63.

[24] E. Ferapontova, L. Gorton, Bioelectrochemistry 55 (2002) 83-87. 